\title{
A SCIENTIST DOES NOT HAVE TO BE HUMAN?
}

\section{Dorota Szymborska*}

\begin{abstract}
We, as humans appropriated science. A scientist is associated only with a human being. It doesn't have to stay that way. Non-protein scientists may appear sooner than expected. We will be challenged soon. A new legal and ethical code will be needed, and above all, a redefinition of the concepts of science and scientist seems to be urgent to formulate. The appearance of superintelligence and machines in science will mean the need to re-evaluate its operation. Let's start noticing the law of artificial intelligence $(\mathrm{Al})$, to build inclusive science with machines.
\end{abstract}

Keywords: Artificial Intelligence, Science, Scientist, Superintelligence, Al, Science Philosophy, New Technologies

\footnotetext{
* Dorota Szymborska, Maria Curie-Skłodowska University, Lublin, Poland e-mail: : dotaszymborska@gmail.com | ORCID: https://orcid.org/0000-0003-3983-3934
} 
A scientist is someone who "does science". An expert in a certain field who conducts research, uses scientific methods, seeks for answers to scientific questions, and is able to prove the answers. In another words: a scientist is an expert in a certain field, who conducts research using scientific methods, and can prove their answers. Scientist should strive at objectivity, attack new problems about the material world1.

In the Dictionary of Polish Language (Stownikjęzyka polskiego pod red. W. Doroszewskiego nd.: naukowiec), a scientist is defined as "a human who deals with science". In English-language literature, however, you do not need to be a human to conduct scientific research ${ }^{2}$. There were not scientists before the 19th century, the word "scientist" came into common use about two centuries ago, introduced by a science historian William Whewell (Lehoux 2011: 39).

There is a question regarding to what extent a scientist must be human to be revealing, independent and creative ${ }^{3}$. J ust as the concept of a scientist had not occurred before Whewell, as there was only a "natural philosopher". Now it is time to consider whether we should assume that only people can be involved in science. What about artificial intelligence $^{4}$ (Poole, Mackworth, Goebel 1998: 1) or even superintelligence? For the sake of this paper, I assume that superintelligence ${ }^{5}$ still works in our computational reality and it does not use any other logic that may belong to e.g. quantum computers ${ }^{6}$.

Let us start with the features of scientific superintelligence. Firstly, so far it does not require remuneration, it cannot own what it creates,

\footnotetext{
' Understood as world seen from physical, chemical or biological perspective not material science as a design of new materials (solids).

2 "A scientist is someone who systematically gathers and uses research and evidence, making a hypothesis and testing it, to gain and share understanding and knowledge" (The Science Council nd).

3 See Marcel-Paul Schützenberger, who was deeply against Neo-Darwinism (as a mixture of Darwinism and genetics), this mathematician was focused on formal results in mathematics. For more see: Chomsky, Schützenberger 1963.

4 Using Bostrom's definition of superintelligence (Bostrom 2006).

5 I will focus on superintelligence instead of AGI - Artificial General Intelligence (Hodson 2019).

${ }^{6}$ Idea of a quantum computer came in IX century, and been explored firstly only theoretically now in more practice way, for more see: Feynman 1982.
} 
and its creativity belongs to the owners of the company that programmed or created it. Secondly, it is independent, as there are no feelings 7 , they do not affect the test results in any way ${ }^{8}$. Thirdly, it draws knowledge from data, and it is based on a training set that can be huge with the current computing power 9 .

When it comes to "free of charge" superintelligence, nowadays it does not require a full-time salary. In J anuary 2020, a court in China recognized the copyright of artificial intelligence for a newspaper article (Winiger 2020). So far, this has been an unprecedented verdict because the courts had not recognized before that artificial intelligence may own intellectual property. Since then, no other verdict has been issued in the precedent judiciary that would recognize artificial intelligence as the owner of anything ${ }^{10}$. As McCombs at al. (2020) summarised: "The term $\mathrm{AI}$ inventions is an umbrella that covers two categories: inventions that utilize AI and inventions that are created by AI".

AI's lack of feelings will allow for conducting any study objectively. Both qualitative and quantitative methods will be used to the full, nothing will be omitted or underestimated, obviously, with the assumption of sufficiently good software. This assumption is necessary because in the case of weak or incomplete software, it is not possible to conduct the test properly. What is supposed to make AI different from a human scientist is quality, lack of bias and overall view, thanks to machine learning, and deep learning process programs can analyze data in a more versatile way than people (Moravec 1998).

\footnotetext{
7 Hochschild (2003: 10-11) wrote about labour of feelings: "To uncover the heart of emotional labour, to understand what it takes to do it and what it does to people, I have drawn on elements from all three discourses. Certain events in economic history cannot be fully understood unless we pay attention to the filigreed patterns of feeling and their management because the details of these patterns are an important part of what many men and women do for a living".

8 Feelings understood according to the dictionary definition (Merriam-Webster nd.: feeling).

9 Following Collins dictionary: "Computing is the activity of using computer and writing programs for it" (Collins Dictionary nd.: Computing - power). More generally, in technical language computing power is based on: response time (for a given amount of data), rate of processing work and data compression and decompression and data transmission.

10 State for 1 May 2020.
} 
According to Nick Bostrom's understanding of superintelligence, programs will analyse data better than people. As he wrote in 1997: "By a »superintelligence« we mean an intellect that is much smarter than the best human brains in practically every field, including scientific creativity, general wisdom and social skills. This definition leaves open how the superintelligence is implemented: it could be a digital computer, an ensemble of networked computers, cultured cortical tissue or what have you. It also leaves open whether the superintelligence is conscious and has subjective experiences" (Bostrom 2006: 11).

So far, superintelligence has definitely beaten "protein scientists". Before analyzing whether we are already dealing with superintelligence and not just AI, it is worth noting that in some areas, it is difficult for scientists to win the race against AI. An example could be describingXray images or magnetic resonance imaging and diagnosing ${ }^{11}$. A skilled radiologist may not detect abnormalities that AI detects; moreover, even a top-class specialist is not able to memorize as many images as a program can do. The speed and efficiency of AI in this case is incomparably greater than human capabilities.

However, even the best programs (AI) work on the basis of data entered by people; focused on deep learning they can recognize new, preexisting but overlooked health issues in photos or studies, but still it all starts with the data provided by doctors and human scientists. Unlike physicians, AI doesn't matter for what it searches. The situation would be different if superintelligence was conducting this research. On the one hand, it could learn to detect tumors or changes visible in research, but not yet discovered by human doctors, or it could follow a completely different path, recognizing that it makes no sense to find irregularities

\footnotetext{
"A new artificial intelligence algorithm can reliably screen chest $X$-rays for more than a dozen types of disease, and it does so in less time than it takes to read this sentence, according to a new study led by Stanford University researchers" (Armitage 2018).
} 
and concentrate on something completely different while viewing photos or other test results. The inhumanity of superintelligence makes it completely unpredictable (Thomas 2016).

In the context of scientific research, the topic of curiosity and inventiveness of research is important. A scientist not only conducts research but also finds their topics. AI performs tasks, while superintelligence can create these tasks by itself. At the current stage of knowledge, we cannot yet answer whether superintelligence can be curious about the world, and we do not know whether it will be the world for superintelligence. We see scientific research from the perspective of protein scientists (human beings) who have worked in a similar way for centuries. Philosophers of nature like Francis Bacon, J ean-J acques Rosseau, even Thomas Hobbes, as they were previously called, dealt with descriptions and attempted to understand the surrounding world. In the case of superintelligence and its scientific impediment, we do not know what will become its research subject and how these studies will take place. This, here the most important issue arises that superintelligence does not necessarily have to conduct research that will be beneficial for humanity. It can go in a direction unknown to us by conducting research and seeking solutions that will be important and useful.

The coexistence of human and machine scientists can be a peaceful coexistence or a war rivalry. Therefore, at the current development of $\mathrm{AI}$, it is essential to create clear laws regarding inhuman intelligence. Here we touch upon the problem of machine rights and robot rights. They are currently based on what Isaac Asimov proposed years ago. First Law: A robot may not injure a human being or, through inaction, allow a human being to come to harm. Second Law: A robot must obey the orders given it by human beings except where such orders would conflict with the First Law. Third Law: A robot must protect its own existence as long as such protection does not conflict with the First or Second Laws (Asimov 1950: 40). 
Later Asimov added the Zero Law: A robot may not harm humanity or, by inaction, allow humanity to come to harm. This was intended to prevent potential ethical problems related to the progress of both robots (machines) and humanity. Currently, computing powers are increasing, and the introduction of a quantum computer can completely change the capabilities of machines or robots.

Sometimes development takes place through evolution, and sometimes through revolution. It is not known what the case will be in terms of AI or superintelligence. Nowadays, as it has already been pointed out, machines and programs have no rights. Here you can find an analogy to what happened in the past. In ancient Greece, only citizens had rights. The citizen was a free man, he created the law for the rest of society: slaves and women. With the fall of slavery, the number of people who could have legislated increased (Pattinson 2015).

In Europe in the seventies, the last state: Switzerland (Switzerland's Long Way to Women's Right to Vote 2020) granted women's suffrage. With the development of humanity, not only the view on who is a citizen has changed but also the one on who can have certain rights. A few centuries ago, it was unthinkable to recognize the rights of a child or of a mentally ill person (Niveau 2004). Then came the time to grant animal rights (Regan 1985), nowadays there are also discussions about plant rights (Vesilind, Gunn 1998: 94).

The issue of robot and machine rights has been only recently raised. People benefit from the work of AI. AI not only provides programs but also creates art. Works created by AI are put up for auctions, some reaching considerable money that goes to human software owners.

The coexistence with machines, AI or superintelligence will require changes in legislation (Butein 2019). There are several possibilities for creating a law for AI and superintelligence. It might be done only by people, or by people in cooperation with machines, or machines themselves might propose legal solutions. In my opinion, the solution involv- 
ing the cooperation of people and machines should guarantee establishing a law that will respect both people and machines (Iphofen, Kririkos 2019; The Legal Tech Blog 2017).

Certainly, a lot of work will have to be devoted to preparing a new copyright law ${ }^{12}$ regarding medical or judicial errors. As people, we need to ensure that $\mathrm{AI}$ protects our devices. At some point, the goals of superintelligence and people can differ significantly, which is why it is so important now to develop new laws that, on the one hand, will protect human life, while on the other will recognize, for example, property rights or copyrights of machines. There is a big challenge for lawyers because it involves writing codes from scratch, creating the law from scratch (Kizrak 2019). Finally, the most important thing is how the law will recognize AI (Miller nd.), whether it will have a legal personality or a completely new creation. All these changes are also needed if we think of a "non-protein scientist".

If we assume that a "protein scientist" and superintelligence will have their rights/law, not necessarily identical, but based on a compromise, then we face the problem of a multitude of sciences. As if that was not enough, human scientists can have their scientific categories and superintelligence theirs. These teachings can touch, cover or follow completely different paths.

If we imagine human and nonhuman scientists, then suddenly, the area of scientific research changes completely. We face a more significant problem: whether the concept of science should be redefined and, if so, by whom. A dictionary definition states: „Science is the study of the nature and behavior of natural things and the knowledge that we

12 "Regarding Al as a tool to create works, we have to be aware that even though Al seems to be equivalent to the human mind (as the notion of »intelligence « suggests), in reality Al is still far from being really »intelligent «. Much depends on the definition of »intelligence «: if »intelligent « is understood as finding new ways not already known, Al may be called »intelligent « as it can detect new relationships in big data heaps, which was not possible earlier. Furthermore, Al can learn from previous errors and mistakes and improve the patterns of its program. Thus, some argue that the author no longer has sufficient control over how the work is being created and under which conditions" (Spindler 2019). 
obtain about them" (Collins Dictionary: Science) or in more detail: Science, any system of knowledge that is concerned with the physical world and its phenomena and that entails unbiased observations and systematic experimentation. In general, a science involves a pursuit of knowledge covering general truths or the operations of fundamental laws (The Editors of Encyclopaedia Britannica nd: Science).

Even in the basic definitions of science, there is the question of general truths. Here we face the first challenge, which may be general truths (Williams 1996) in relation to science (Wilson 1999) taught by people, which we are aware of, whereas in regard to machines a great unknown question appears.

The goal of research (Thomas G. Carpenter Library nd.) conducted by human scientists is to find answers to previously posed scientific questions and improve the condition of all humanity. By improving, I understand both support in technical sciences and the humanities, which serves to improve the quality of life (Numbeo 2020). I understand the role of a scientist as a desire to contribute with his research and to work to either solve problems or propose solutions that can lead to their elimination.

The environment in which human scientists' function and operate is an academy. Universities and research centers are not only the workplace but also the activities of scientists.

Over the years, the structure of the academy has developed as a result of various responses, for example, the evaluation or accounting of scientists, sometimes the way of awarding academic titles. Despite the changes, the structure and mode of operation remain similar. It starts with exams, which are a pass to the university or polytechnic, then the process of studying, obtaining the first title: a Bachelor's or Master's degree (Cyranoski et al. 2011). Next, there are doctoral studies and schools, habilitation or professorships (Kwok 2017). All go through the passage of specific and previously known career paths of scientific promotion. 
One can criticize the operation of academic structures, see political decisions in them, or undermine the autonomy of academic units, but this never cancels the system developed over the years. It is important that nowadays, a scientist is a person working either in an academy or in a research center (Gupta, Govindarajan 1991). Often, research centers are either connected or are part of polytechnics or universities. Thus, a scientist is a person whose level of advancement of knowledge is monitored, subjected to independent assessment, and a specific scientific title refers to the achievements of the individual in the field of science (Lightman 2011: 367).

Even the not-well-functioning academy allows for a fairly transparent assessment of scientists. It is important because so far, AI has no criteria for scientific assessment, usefulness or awarding scientific titles. $\mathrm{AI}$ is evaluated in terms of the accuracy of its activities, the computing power it uses or requires for testing. In the case of superintelligence, we will face new challenges. One of them will be the assessment of the scientific level, both of the works of superintelligence (Bostrom 2002: 9) and the algorithm/ program/machine itself.

J ust as a human scientist can be demanded and evaluated, so in the case of superintelligence we do not have a machine academy yet. That this is a necessary element is beyond doubt, as is the emphasis on the need to develop common human/ machine standards to which all scientists will be subject.

To develop such standards, you must first recognize AI, superintelligence as a partner for such talks. For this to happen, changes in the law are needed first, and then it will be possible to create research centers connecting human and inhuman scientists. This will be possible if superintelligence (Bostrom 2014) wants to interact with human scientists. You must also consider a completely different scenario in which superintelligence does not want to interact and co-create with people; its goals will be separate. In the worst-case scenario, this means that 
superintelligence will seek to destroy what is human or what will interfere with its goals (Santos-Lang 2014).

It seems impossible to create a weapon against superintelligence and its "scientists" as the very concept of superintelligence implies that it will outweigh people with its capabilities. Therefore, the first step that should be prepared and worked out as soon as possible is a legal recognition of AI and a guarantee of peaceful coexistence. It sounds like signing surrender before taking war. The most important thing is not to lead to such a war, because people are doomed to lose.

What can already be proposed is to prepare changes in the already existing law, so far only in human commissions, which will take into account the emergence of superintelligence, and then a joint human / inhuman preparation of a new law.

As far as "non-protein scientists" are concerned, in the event of recognition of the laws of superintelligence and the creation of new codes, a uniform system of scientific evaluation of superintelligence should also be created (Müller, Bostrom 2016). This is a human proposition; we should be prepared for what superintelligence will propose, which can be a completely different solution that we are not able to foresee at the moment. Therefore, the measure of openness and development of science in the future should be the peaceful coexistence of human and inhuman scientists. One can imagine not only using the help of superintelligence in solving human problems but also participation in solving problems of superintelligence by human scientists. This may resemble an exchange and a proposal for entirely new solutions. At the same time, we should take into account that our human, but also the scientific level of development will not be anything interesting for superintelligence. For a simple reason: it will be at a much higher level of development.

Let us appreciate what we have now: that we can be scientists, ask questions and enjoy the benefits of technology, but let us also remember that this is not a permanent state. I believe that we are no longer able to stop AI development, so the only solution is peaceful coexistence. 
References

Armitage, H. (2018). AI matched, outperformed radiologists in screening X-rays for certain diseases. Medical Xpress. https:// medicalxpress.com/news/ 2018-11-ai-outperformed-radiologists-screeningx-rays.html [12.20.2020].

Asimov, I. (1950). I, Robot. London: Dobson.

Bostrom, N. (2002). Existential Risks: analyzing human extinction scenarios and related hazards. Journal of Evolution and Technology, 9. http://jetpress.org/volume9/ risks.html [12.20.2020].

Bostrom, M. (2006). Howlong before superintelligence? Linguistic and Philosophical Investigations, 5(1), 11-30.

Bostrom, N. (2014). Superintelligence: Paths, Dangers, Strategies. Oxford: Oxford University Press.

Butein, M. (2019). Towards Intelligent Regulation of Artificial Intelligence. European Journal of Risk Regulation Vol. 10, Iss. 1, 41-59.

Chomsky, N., Schützenberger, M.-P. (1963). The Algebraic Theory of Context-Free Languages. [in:] Computer Programming and Formal System. (Eds.) Braffort, P., Hirschberg, D. Amsterdam: North Holland Publishing Company. 118-161.

Collins Dictionary. (nd.), https:// www.collinsdictionary.com [12.20.2020]. Cyranoski, D., Gilbert, N., Ledford, H., Nayar, A., Yahia, M. (2011). Education: The PhD Factory. Nature 472, 276-279. https:// doi.org/ 10.1038/472276a.

The Editors of Encyclopaedia Britannica. (nd.). Science. Encyclopaedia Britannica, https:// www.britannica.com

Feynman, R. (1982). Simulating Physics with Computers. International Journal of Theoretical Physics Vol. 21, No. 6/ 7, 467-488.

Gupta, A., Govindarajan, V. (1991). Knowledge Flows and the Structure of Control Within Multinational Corporations. The Academy of Management Review Vol. 16, No. 4, 768-792. https://doi.org/10.5465/ amr.1991.4279628. 
Hochschild, A.R. (2003). The Managed Heart: Commercialization of Human Feeling. Berkeley- Los Angeles: University of California Press. Hodson, H. (2019). "DeepMind and Google" the battle to control artificial intelligence. Economist 1843. https://www.economist.com/ 1843/2019/03/01/ deepmind-and-google-the-battle-to-control-artificial-intelligence [12.20.2020].

Iphofen, R., Kririkos, M. (2019), Regulating artificial intelligence and robotics: ethics by design in a digital society, Contemporary Social Science.

Kizrak, A. (2019). AI vs. Lawyers: The Future of Artificial Intelligence and Law, Interesting Engineering Blog, https://ayyucekizrak.medium.com/ ai-vs-lawyers-the-future-of-artificial-intelligence-andlaw-3c48d61eb2e.

Kwok, R. (2017). Flexible working: Science in the gig economy. Nature 550, 419-421. https:// doi.org/ 10.1038/ nj7676-419a.

The Legal Tech Blog. (2017). AI in Law: Definitio, Current Limitations and Future Potential. https://legal-tech-blog.de/ai-in-law-definition-current-limitations-and-future-potential.

Lehoux, D. (2011). Natural Knowledge in the Classical World. [in:] Wrestling with Nature: From Omens to Science. (Eds.) Shank, M., Numbers, R., Harrison, P. Chicago- London: The University of Chicago Press. 37-58.

Lightman, B. (2011). Science and the Public. [in:] Wrestling with Nature: From Omens to Science. (Eds.) Shank, M., Numbers, R., Harrison, P. Chicago- London: The University of Chicago Press. 337-376

MoCombs, D. at al. (2020), Navigation A New Realm: AI and Patent Law. Law.com. https:/ / www.law.com/legaltechnews/ 2020/ 07/ 16/ navi gating-a-new-realm-ai-and-patent-law/ ?slreturn $=20210007091827$ [12.20.2020]

Merriam-Webster. (nd.) https:// www.merriam-webster.com/ dictionary/ feeling [12.20.2020]. 
Miller S. (nd.). Part II: The Future of Artificial Intelligence, Thomson Reuters. https:// legal.thomsonreuters.com/ en/insights/articles/ future-of-artificial-intelligence-robot-lawyer-army-or-not.

Moravec, H. (1998). When will computer hardware matches the human brain? Journal of Transhumanism Vol. 1, 10-22.

Müller, V.C., Bostrom, N. (2016). Future Progress in Artificial Intelligence: A Survey of Expert Opinion. [in:] Fundamental Issues of Artificial Intelligence. (Ed.) Müller V.C. New York: Springer. 553-571. Niveau, G. (2004). Preventing human rights abuses in psychiatric establishments: The work of the CPT. European Psychiatry Vol. 19, Iss. 3, 146-154. https:// doi.org/ 10.1016/j.eurpsy.2003.12.002.

Numbeo. (2020). Quality of Life Index by Country 2020. https:// www.numbeo.com/ quality-of-life/rankings_by_country.jsp.

Pattinson, D. (2015). The Human Rights Act and thedoctrineat precedent. Legal Studies Vol. 35, No. 1, 142-164. https:// doi.org/ 10.1111/ lest.12049. Poole, D., Mackworth, A., Goebel, R. (1998). Computational Intelligence: A Logical Approach. New York: Oxford University Press.

Regan T. (1985). The Case for Animal Rights. [in:] In Defence of Animals. (Ed.) Singer, P. New York: Basil Blackwell. 13-26.

Santos-Lang, C. (2014). Our responsibility to manage evaluative diversity. ACM SIGCAS Computers \& Society Vol. 44, Iss. 2, 16-19. The Science Council. (nd.) Our definition of a scientist. https://sciencecouncil.org/ about-science/ our-definition-of-a-scientist/ Stownik języka polskiego pod red. W. Doroszewskiego. (nd.), https:// sjp.pwn.pl/ doroszewski/ naukowiec;5456600.html [12.20.2020]. Spindler G. (2019). Copyright Law and Artificial Intelligence. IIC - International Review of Intellectual Property and Competition Law Vol. 50, 1049-105. 1https:// doi.org/ 10.1007/ s40319-019-00879-w. Switzerland's Long Way to Women's Right to Vote (nd.). Female Suffrage. http:/ / history-switzerland.geschichte-schweiz.ch/ chronologywomens-right-vote-switzerland.html [12.20.2020]. 
Thomas G. Carpenter Library. (nd.). What is Original Research? Original research is considered a primary source, University of North Florida, https:/ / web.archive.org/ web/ 20110709085129/ http:/ / www.unf.edu/ library/guides/ originalresearch.html.

Thomas, J . (2016). In defence of philosophy: a review of Nick Bostrom, Superinteligence: Paths, Dangers, Strategies, Journal of Experimental \& Theoretical Artificial Intelligence Vol. 28, Iss. 6, 10891094.

Vesilind, P.A., Gunn, A.S. (1998). Engineering, ethics, and the environment. Cambridge: Cambridge University Press.

Williams, M. (1996). Truth. Encyclopaedia of Philosophy. Ann Arbor: Macmillan.

Wilson, E.O. (1999). "The natural sciences". Consilience: The Unity of Knowledge. New York: Vintage.

Winiger A. (2020). Shenzhen Court Rules AI-Generated Articles are Entitled to Copyright Protection. https://www.slwip.com/reso urces/ shenzhen-court-rules-ai-generated-articles-are-entitled-toco pyright-protection/ ?fbclid=IwAR3jKT9xnRLxvh71mXss8VwSUbuu RjZU9XLE-DlQ0gQlnTq_lEKU52q9UhA. 